\title{
David Oliver: "Ghost wards" and rota gaps show the need for official safe staffing levels
}

\author{
David Oliver consultant in geriatrics and acute general medicine
}

Berkshire

In April the Guardian reported NHS England figures showing that hospitals were "mothballing" at least 82 wards containing 1400 empty beds. ${ }^{1}$ There simply weren't the staff to keep them viable, so they became "ghost wards."

In March the Faculty of Intensive Care Medicine had reported that most intensive care units are regularly forced to transfer patients to other facilities, partly because they can't safely provide the nurses needed to staff their full bed base and keep beds open. ${ }^{2}$ And the BBC reported in February that hospital corridors are increasingly used in effect as emergency wards. ${ }^{3}$ One in nine advertised NHS nursing vacancies is unfilled, ${ }^{4}$ and nurses often have to soldier on while several colleagues are missing from shifts.

The failure of national leadership around safe nursing levels has meant ducking the issue of formal guidance on nurse-patient ratios and skill mix. Decisions have been devolved back to local nurse managers, and we've seen no consistency in developing well evidenced guidance on safe nurse staffing. ${ }^{56}$

I realise that the number of staff you need can flex a bit. But local nursing directors do set local target nursing numbers for each shift and clinical area. When it comes to my fellow acute hospital doctors, working with now endemic rota gaps and unfilled posts, ${ }^{7}$ I don't see even these protections existing. The case of Hadiza Bawa-Garba and the GMC's response focuses the mind on the implications of having no such protections. ${ }^{8}$

Gaps or not, general hospitals must keep on absorbing front door demand: they must keep looking after admitted patients, however many pile in. Numbers can reach a tipping point, the situation can become unmanageable, and serious corners can end up being cut.

Closing down bays or wards is rarely used to help doctors in these situations. Quite the reverse. The solution is often to burden them with more outlying patients or open more beds in extra clinical areas.

Closing down bays or wards is rarely used to help doctors in these situations. Quite the reverse
It's surely time to set down a formal marker of safe staffing levels. We need to do this for patient safety and because of the risk of doctors facing regulatory action, damaging their own health, undermining their own training, or disappearing from the workforce.

We can consider how many doctors we need at each grade to look after a particular number of patients with a certain level of acuity and dependency. We can set down all the markers we like for a safe ratio of doctors to patients. These numbers may not be achieved, just as target nursing numbers are often not practicably filled.

But surely there's an urgent case for setting these numbers out clearly-and for regulators to make it clear what safe staffing numbers look like. It may just focus the mind.

Competing interests: See bmj.com/about-bmj/freelance-contributors/david-oliver. Provenance and peer review: Commissioned; not externally peer reviewed.

Campbell D. Revealed: 82 "ghost wards" containing 1400 empty NHS beds. Guardian 13 April 2018. https://www.theguardian.com/society/2018/apr/13/revealed-82-ghost-wards1400-empty-beds-nhs-england.

2 Campbell D. NHS intensive care units sending patients elsewhere due to lack of beds. Guardian 7 March 2018. https://www.theguardian.com/society/2018/mar/07/patientsturned-away-intensive-care-lack-beds-shortage-hospitals.

3 Triggle N. NHS pressure: Hospital corridors "the new emergency wards." BBC News 8 Feb 2018. www.bbc.co.uk/news/health-42989181.

4 NHS Providers. Summary of vacancy, shortfall and fill rate data for the clinical workforce. Nov 2017. https://nhsproviders.org/media/3903/summary-of-vacancy-shortfall-and-fillrate-data-for-the-clinical-workforce.pdf.

5 Oliver Dconsultant in geriatrics and acute general medicine. David Oliver: Nurse staffing levels are still not safe. BMJ 2016;353:i2665. 10.1136/bmi.i2665 27177770

Safe Staffing Alliance. www.safestaffing.org.uk/.

$\begin{array}{ll}6 & \text { Safe Staffing Alliance. www.safestaffing.org.uk/. } \\ 7 & \text { Royal College of Physicians. 2016-17 census (UK consultants and higher specialty }\end{array}$ trainees). 28 June 2017. https://www.rcplondon.ac.uk/projects/outputs/2016-17-censusuk-consultants-and-higher-specialty-trainees.

8 Clarke R. The Hadiza Bawa-Garba case is a watershed for patient safety. 29 Jan 2018 https://blogs.bmj.com/bmj/2018/01/29/rachel-clarke-the-hadiza-bawa-garba-case-is-awatershed-for-patient-safety/.

Published by the BMJ Publishing Group Limited. For permission to use (where not already granted under a licence) please go to http://group.bmj.com/group/rights-licensing/ permissions 